\title{
Un baño Sa'adí con influencia otomana bajo el palacio al-Badī' de Marrakech
}

\author{
A Saadian Bath with Ottoman Influences Under \\ al-Badī‘ Palace of Marrakech
}

\author{
Antonio Almagro \\ Escuela de Estudios Árabes, CSIC. Granada \\ http://orcid.org/0000-0001-9907-5149
}

\begin{abstract}
Analizamos en este breve estudio unos restos excavados dentro del gran patio del palacio alBadī' de Marrakech, que corresponden a un hammām cuya desaparición estuvo probablemente causada por la construcción del gran palacio levantado por el sultán sa'adí Aḥmad al-Manșūr en 1578. El empleo en ese edificio termal de formas características de los baños otomanos construidos en esa misma época induce a pensar que su construcción fuera realizada por el hermano y predecesor de al-Manșūr, 'Abd al-Malik, entre 1576 y 1578.

Palabras clave: Marruecos; Sa'adíes; ham$m \bar{a} m$; influencia otomana; sala octogonal; sala hexagonal.
\end{abstract}

We analyze in this brief study the remains excavated in the great courtyard of the al-Badi ${ }^{6}$ Palace in Marrakech, which correspond to a hammām, whose disappearance was probably caused by the construction of the great Palace erected by the Saadian Sultan Ahmad alManșūr in 1578. The use in that thermal building of some characteristic forms of the Ottoman baths built at the same time suggests that its construction was performed by the brother and predecessor of al-Manșūr, 'Abd al-Malik, between 1576 and 1578 .

Key words: Morocco; Saadians; hammām; Ottoman influence; octagonal room; hexagonal room.

En la mitad norte del lado oeste del gran patio del palacio al-Badī' de Marrakech (Fig. 1), construido por el sultán sa'adí Aḥmad al-Manșūr entre 1578 y 1594, hay en la actualidad una zona rehundida, fruto de una excavación realizada en circunstancias que desconocemos en detalle, y en la que se pueden ver diversas estructuras murarias de las que no tenemos noticia de que se haya dado cuenta en ninguna publicación. Todo indica que esa excavación se realizó en los últimos años del Protectorado, quizás a la vez o de forma inmediata al desescombro, lim- 


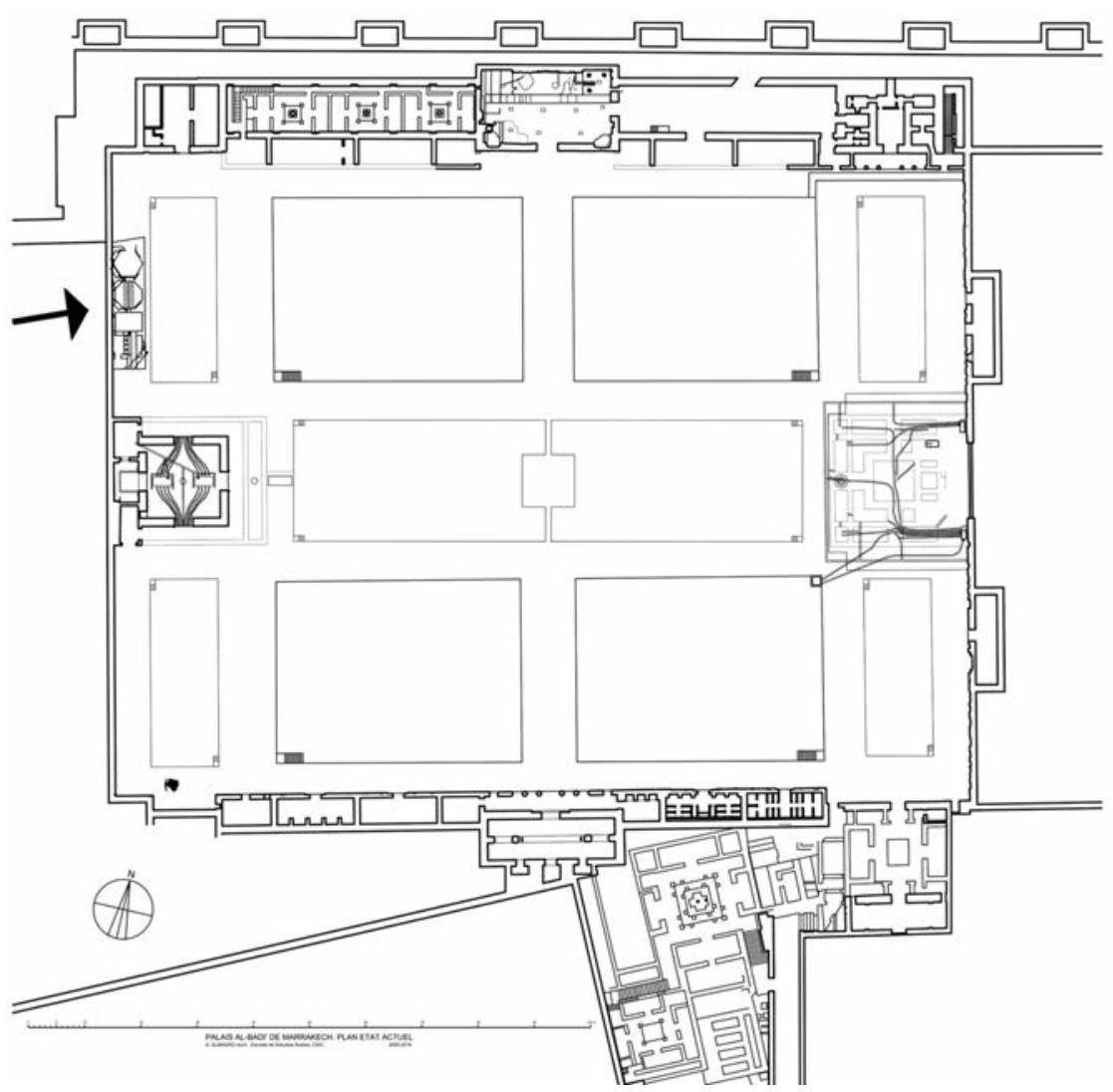

Figura 1. Planta general actual del palacio al-Badi de Marrakech (la flecha marca la situación de la excavación del baño) (A. Almagro).

pieza y primeras restauraciones del conjunto sa'adí efectuadas en los años cincuenta del pasado siglo. La única referencia concreta es la que proporciona Gaston Deverdun quien hace mención de tres salas descubiertas por A. Nolot, Inspector de Monumentos Históricos de Marrakech, en el ángulo noroeste de al-Badī ${ }^{`}$. Este autor pone estas estructuras en relación con tres salas que menciona Luis del Mármol Carvajal al describir el palacio del sultán 'Abd Allāh al-Gālib en la qașba de Marrakech. Del cotejo de la descripción de Mármol con las

${ }^{1}$ Deverdun, Marrakech, des origines à 1912, p. 361. 
estructuras que vamos a describir resulta fácil deducir que se trata de cosas distintas ${ }^{2}$. Como analizaremos más adelante, estas estructuras parecen anteriores a la construcción del palacio de al-Manșūr y muy probablemente corresponden a un baño o hammām, que por su singularidad e interés vamos a tratar de analizar en las páginas que siguen.

El área excavada tiene unas dimensiones de casi seis metros de ancho por veintitrés de largo (Fig. 2). Los dos lados largos de la zanja están limitados por estructuras de muros pertenecientes al palacio de al-Mansuūr mientras que los lados cortos son simples cortes en el terreno contenidos por muros modernos ${ }^{3}$. El límite oeste de la excavación está formado por el muro occidental de cierre del palacio y por su cimentación. En la mayor parte de esa zona el muro está reconstruido en época muy reciente, aunque su cimentación parece ser original ${ }^{4}$. El borde oriental de la excavación lo conforma la parte externa del muro de la alberca situada al norte del pabellón occidental del palacio ${ }^{5}$, que aparece con una cara muy irregular pues al estar el estanque hundido en el suelo, sus muros perimetrales, hechos de hormigón de cal, se construyeron usando como encofrado externo el propio borde del hueco abierto en el terreno, lo que les confirió una cara externa rugosa al ser moldeada por la tierra.

${ }^{2} \mathrm{He}$ aquí el texto de Mármol: "En un cuarto de estos tiene hechas tres salas bajas con sus alcobas doradas, y en la de en medio hay tres fuentes de agua, y dos puertas que responden a dos hermosos vergeles de jazmines, laureles, y arrayanes, y de otras muchas flores olorosas, con las calles cubiertas de parras, y de árboles fructíferos, cercados de canceles de reja hechos de madera con puntas de hierro por encima. En el uno de estos vergeles tiene hecho un estanque de agua a manera de alberca de cuarenta varas de largo y más de diez de ancho con muchos azulejos donde va el rey a bañarse de verano" (Mármol, Descripción general de África, p. 31a). Ni por la descripción en sí, ni por el tamaño de las salas ni por la presencia de fuentes y puertas dando a jardines pueden identificarse estos restos con lo descrito. Desgraciadamente no existe ningún otro texto ni documento que pueda relacionarse con estas estructuras.

${ }^{3}$ A los efectos de nuestra descripción consideraremos que la zanja de la excavación tiene orientación norte sur siendo los lados más cortos los correspondientes a esas direcciones.

${ }^{4}$ Toda la parte baja del muro y la cimentación visible están actualmente recubiertas por un revoco de mortero, fruto de una reciente restauración, que hace imposible realizar ningún análisis murario.

${ }^{5}$ Almagro, "Análisis arqueológico del pabellón occidental del palacio Al-Badi’ de Marrakech". 

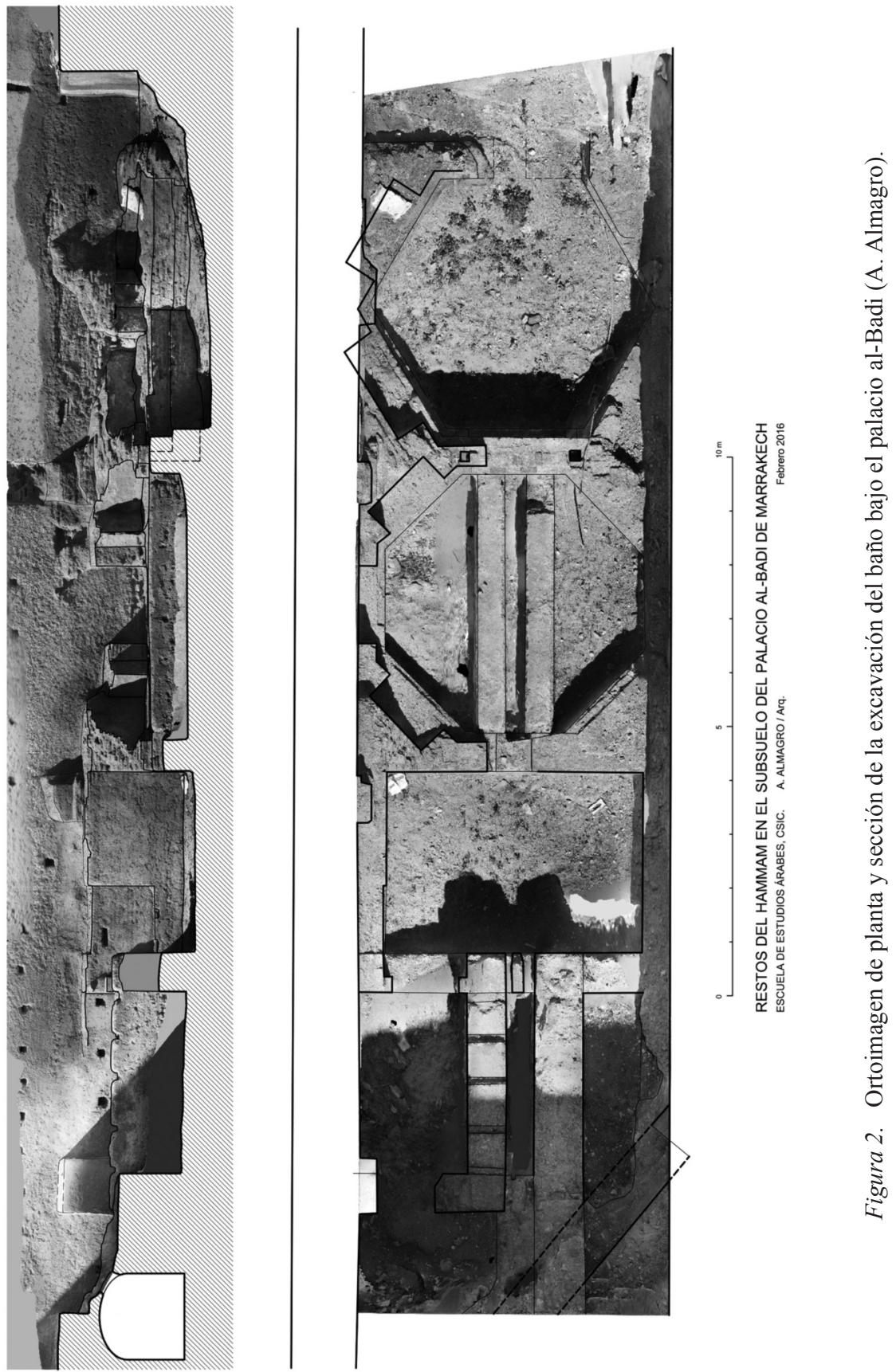

Al-Qantara XXXVIII 2, 2017, pp. 263-285 ISSN 0211-3589 doi: 10.3989/alqantara.2017.009 


\section{Descripción de los restos}

Una primera observación de las estructuras visibles en esta zanja de excavación permite identificar tres espacios o habitaciones, contiguas una a la otra, cuya anchura ocupa la casi totalidad del ancho del área excavada (Fig. 3). En el extremo sur existen otras estructuras más complejas, y en el norte el borde de la excavación, formado por un muro moderno de mampostería, se sitúa muy cerca del extremo de la última habitación, ocultando lo que podría haber más al norte. Estas tres habitaciones, recorridas de sur a norte, tienen plantas rectangular, octogonal y hexagonal respectivamente. Como ya explicaremos con más detalle, todas aparentan haber sido excavadas hasta una profundidad mayor de la cota en que se encontraba su pavimento original, que en todos los casos ha desaparecido.

Como el propio título del trabajo indica y tal y como trataremos de demostrar más adelante, creemos que esta breve suite de habitaciones corresponde a un hammām o baño, cuya construcción, por lo ya insinuado anteriormente, tiene que haber sido anterior a la del palacio construido por Aḥmad al-Manșūr a partir de 1578. Baste para ratificar esta última afirmación el hecho de que tanto el muro perimetral del palacio como el de la alberca se apoyaron sobre las estructuras, ya en ese momento arruinadas, de lo que suponemos fue un baño. En algunos casos incluso no sólo se apoyan sobre muros, sino que cubren o macizan zonas que formaron parte del espacio libre de las habitaciones. Por tanto puede afirmarse que estas estructuras fueron destruidas, o quizás lo estaban ya, cuando se decidió la construcción del palacio. Como ya indicaremos, creemos que fue el primero de estos supuestos el que seguramente tuvo lugar.

Adelantándonos a la argumentación necesaria que realizaremos a continuación, pero para facilitar la descripción de los restos, diremos que la habitación rectangular correspondía a la sala fría o al-bayt al bārid, la octogonal a la templada o al-bayt al-wasțānī y la hexagonal a la caliente o al-bayt al-sajün.

Más al sur de la sala fría existen dos muros paralelos con dirección norte sur, que dejan un estrecho pasaje entre ambos de apenas $0,50 \mathrm{~m}$ de anchura (Fig. 4). El muro occidental, de 0,70 m de espesor, está construido con tapia de hormigón de cal y en su cara superior se aprecian perfectamente las hendiduras dejadas por agujas pasantes. El muro oriental tiene una anchura de $0,91 \mathrm{~m}$ y está hecho también de tapia de 

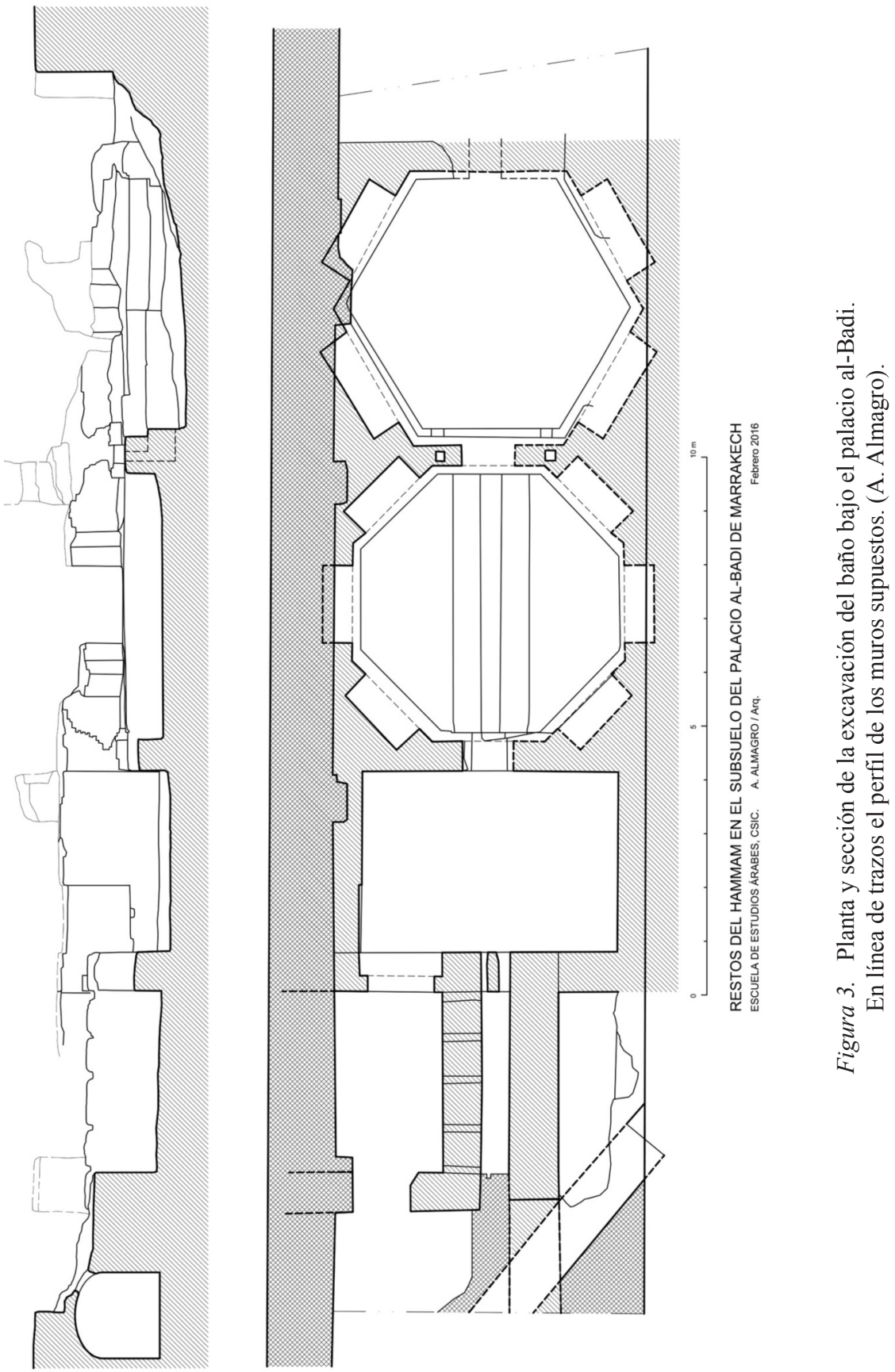

Al-Qanțara XXXVIII 2, 2017, pp. 263-285 ISSN 0211-3589 doi: 10.3989/alqantara.2017.009 
cal en su parte inferior, aunque por encima de un determinado nivel continuaba con fábrica de ladrillo a juzgar por los restos conservados en su extremo sur. Los espacios existentes a ambos lados de estos muros parecen estar desfondados como el resto de la excavación pues los suelos actuales están más de medio metro por debajo de los indicios de los suelos originales. Por ello es muy probable que las fábricas de tapia correspondan a cimentación y que como también veremos en otras zonas las estructuras sobre rasante eran de ladrillo. A este respecto, cabe también indicar que en la parte de fábrica de ladrillo antes mencionada se aprecia un corte que a todas luces parece la jamba de un hueco del que la opuesta ha desaparecido al haberse expoliado el ladrillo del resto del muro hacia el norte.

El estrecho corredor que discurre entre los dos muros y que como veremos debió alojar canalizaciones de agua, quedó taponado a 3,40 $\mathrm{m}$ del muro de la sala fría por una masa de hormigón que por el lado del pasaje presenta una cara plana por haber estado encofrada (Figs. 3 y 4). Este macizado del extremo del corredor está relacionado con la existencia de una atarjea abovedada que en su momento taladró el muro oriental del corredor rompiendo claramente su fábrica original lo que

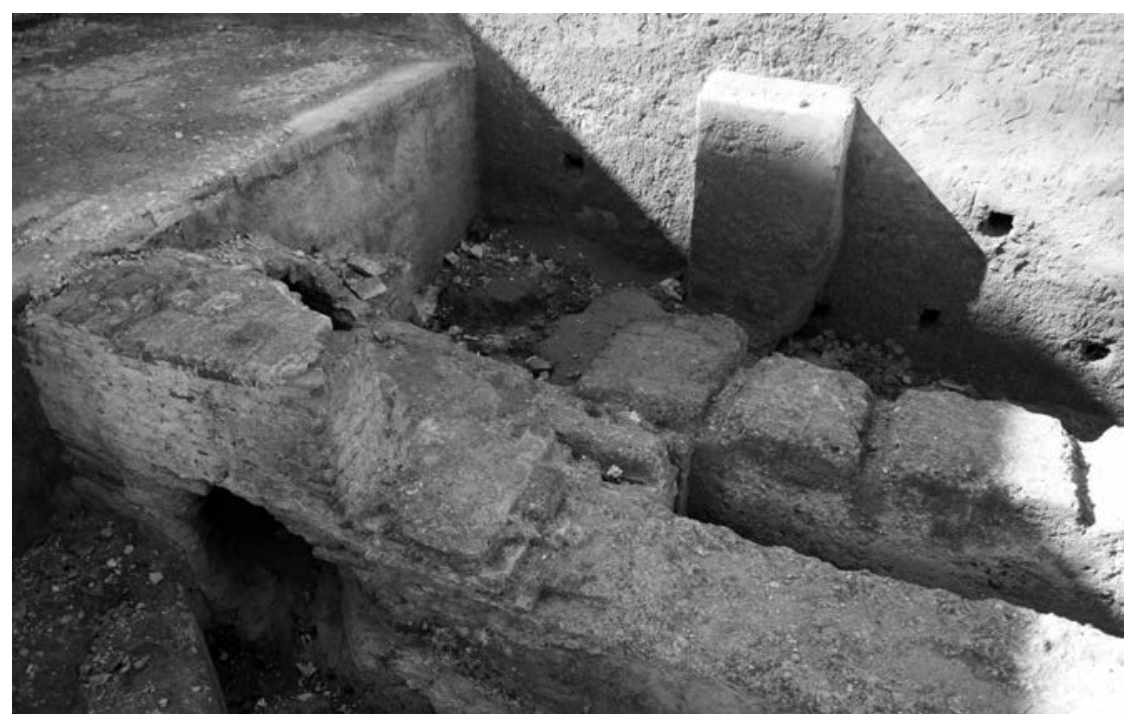

Figura 4. Vista de la zona sur de la excavación con distintas canalizaciones hidráulicas (A. Almagro). 
junto con el macizado del extremo de éste muestra que se trata de una actuación posterior a la construcción del baño, cuando seguramente éste estaba en desuso y posiblemente ya destruido. Aunque requeriría una exploración más completa, puede considerarse relacionado con las estructuras palatinas ejecutadas por al-Manșūr.

Esta atarjea presenta una dirección oblicua respecto a las otras estructuras, lo que vendría a confirmar su falta de relación con ellas. Conserva parte de su bóveda de ladrillo en la zona en que discurre conformada por la masa de hormigón ya descrita que tapona el corredor. Hacia el suroeste la atarjea se introduce en zona no excavada mientras hacia el noreste solo conserva la base y el muro meridional habiendo perdido el del otro lado y la bóveda. Finalmente se introduce por debajo del muro de la alberca, aunque aparece taponada no pudiéndose asegurar si discurre por debajo de ésta o quedó cercenada al construirse el estanque.

Al oeste del estrecho corredor ya descrito existió una habitación cuya dimensión solo conocemos en la dirección norte sur y que era de 3,35 m. En la dirección este oeste no conocemos su medida pues quedó cortada por el muro perimetral del palacio de al-Manșūr. Su cierre oriental es el muro de hormigón que constituye uno de los lados del corredor de servicio hidráulico. Por el lado sur sólo se conserva un tacón de fábrica de ladrillo que parece formar la jamba de un hueco cuya jamba opuesta podría conservarse bajo el cimiento del muro del palacio, aunque hoy resulta irreconocible por haber sido recubierto todo con un revoco informe de mortero en reciente restauración.

En el lado opuesto de esta puerta existe otra claramente definida por la que se accedía a la sala fría (Fig. 5). Sus jambas son de ladrillo como lo debía ser todo el muro en que se abre y que hoy sólo es visible hasta una escasa distancia de la jamba occidental. Esta habitación pudo corresponder al vestuario y sala de reposo del baño de acuerdo con el esquema tradicional de éstos, o en todo caso ser un vestíbulo de paso entre aquél y las salas húmedas. Por esta puerta se accede a la que sin duda fue la sala fría del baño, una habitación rectangular de $4,75 \mathrm{~m}$ x 3,34 m con la dimensión mayor en dirección este-oeste. Los muros que conforman esta habitación son de fábrica de ladrillo salvo el muro meridional que es de tapia de hormigón de cal. La puerta de acceso, de 1,24 m de luz, está situada en el ángulo suroeste y posee mochetas para disponer una carpintería de cierre. Dicha carpintería era de una única hoja que se abatía sobre el muro occidental en el que se practicó un re- 


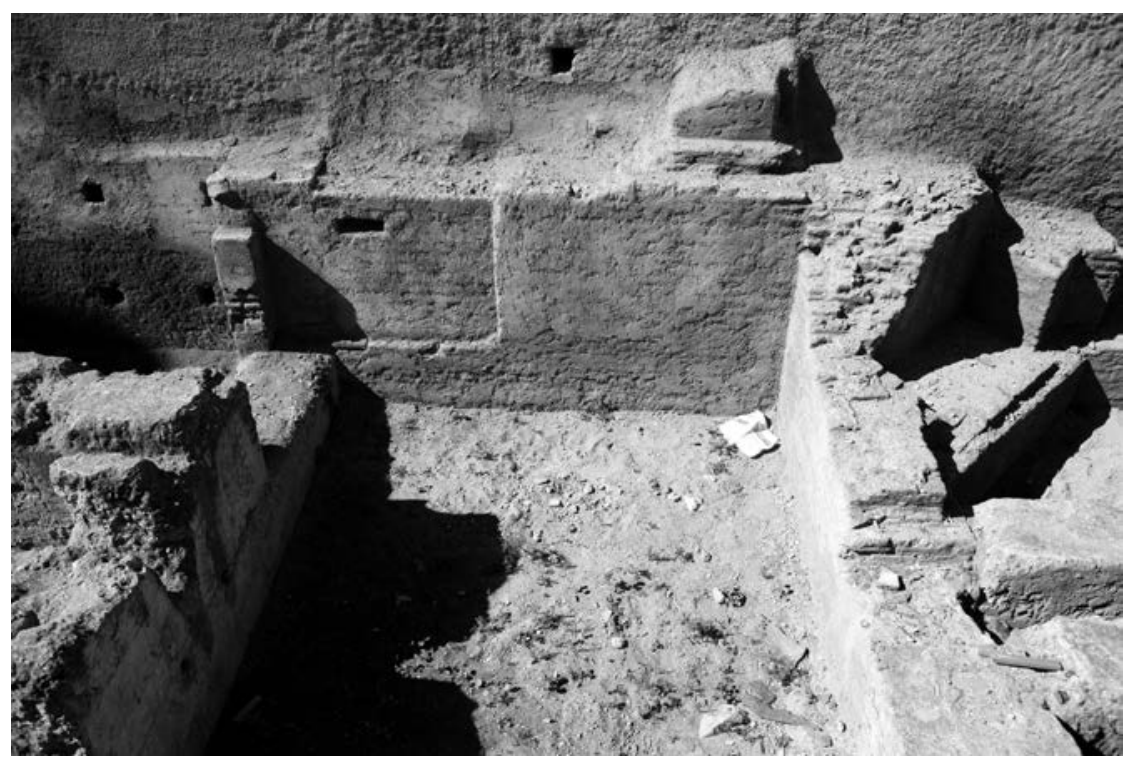

Figura 5. Vista de la sala fría del baño (A. Almagro).

baje para que la puerta quedara enrasada con la pared al quedar abierta. Este rebaje sólo se practicó por encima del nivel del pavimento pues el muro conserva todo su espesor por debajo de ese nivel además de continuar por debajo del umbral de la puerta. La actual sobre excavación de esta sala nos muestra que a través de la cimentación no existe ningún hueco ni paso de ninguna tubería o conducto de humos.

La puerta de acceso a la siguiente sala, la templada, está situada en el centro de la pared septentrional y de ella solo se conserva la jamba oeste. Por simetría respecto del eje de la sala templada puede deducirse que esta puerta tuvo una anchura de $0.94 \mathrm{~m}$, y bajo su umbral el cimiento continúa sin interrupción. Frente a esta puerta, en el muro de hormigón del lado sur existen dos rozas abiertas en todo su espesor, que sin duda sirvieron para permitir el paso de tuberías de agua desde el corredor o estrecho pasaje que antes describimos. De estas rozas, una se abre hasta casi el nivel del pavimento mientras la otra se queda a unos $0.40 \mathrm{~m}$ del primitivo suelo. Se puede interpretar que en ese sitio hubo una pila de agua adosada a la pared cuyo caño de alimentación se abastecería por la roza más alta mientras la que llega casi al nivel del suelo serviría para que por ella discurriera el desagüe. 
La sala siguiente tiene planta octogonal (Fig. 6) y su eje de simetría es prolongación del de la sala anterior. Los lados del octógono miden alrededor de 2,10 m siendo la anchura máxima de la sala unos 5,10 m. Dispone de dos puertas, enfrentadas en dos lados opuestos, una de las cuales es la ya descrita de comunicación con la sala fría. En los otros seis lados en los que no existen puertas, había unos nichos rectangulares de $0,57 \mathrm{~m}$ de profundidad y 1,43 $\mathrm{m}$ de anchura, de los que sólo se conserva el arranque de los del lado oeste. En este caso, también se puede ver la cimentación ya que se ha excavado hasta una profundidad de unos $0.75 \mathrm{~m}$ por debajo del nivel del pavimento, lo que permite apreciar que corre de modo continuo en todo el perímetro sin interrupciones ni huecos. Entre la cimentación y el arranque de los muros existe un retalle de entre 0.15 y $0.20 \mathrm{~m}$. Precisamente enrasando al mismo nivel de la cimentación aparecen dos muros paralelos atravesando la sala de norte a sur, de 0,54 $\mathrm{m}$ de espesor cada uno que dejan un espacio de $0,37 \mathrm{~m}$ entre ambos. Desconocemos cual pudo ser la función de estos muros, pues si hubieran formado parte de la estructura de un hipocausto deberían haber tenido huecos que permitieran el paso del humo y el calor. También en algún sitio de los muros del perímetro debería existir algún hueco que

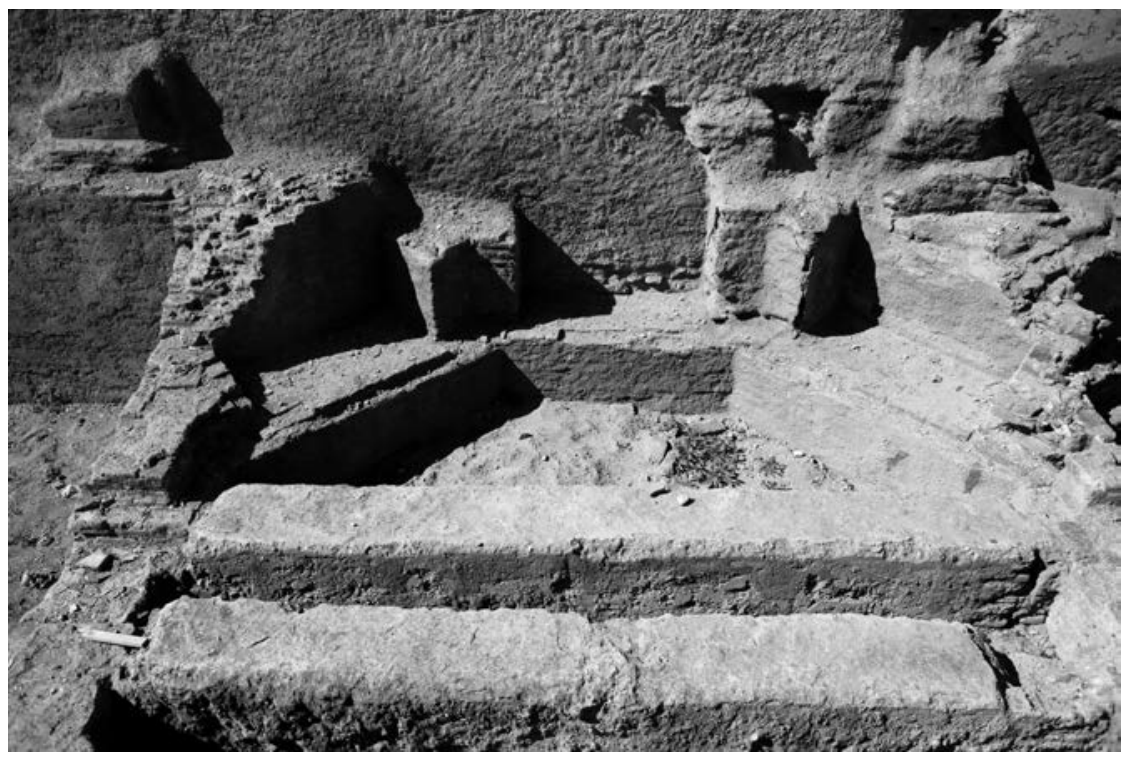

Figura 6. Vista de la sala templada del baño (A. Almagro). 
permitiera ese paso desde alguna de las salas contiguas. Lo mismo cabe decir si hubiera servido el espacio entre ellos para alojar alguna canalización de agua. Por todo ello, resulta un tanto extraña su presencia.

La siguiente sala situada al norte de la antes descrita tiene planta hexagonal y unas características muy semejantes a la anterior (Fig. 7). La anchura entre caras paralelas es de $5.10 \mathrm{~m}$ y la distancia entre esquinas opuestas de $5.80 \mathrm{~m}$. Como en la sala anterior, en cuatro de sus lados tuvo nichos de dimensiones algo mayores que los de la sala contigua, pues sus lados también resultan de mayor longitud. No había nicho en el lado en donde se abre la puerta de acceso, pero no podemos asegurar si lo hubo o no en el lado frontero en donde no cabe pensar que hubo puerta por las razones funcionales que luego comentaremos. No obstante, nada podemos asegurar al haber desaparecido todo resto del muro por encima de la rasante de la cimentación, que incluso en este punto está también parcialmente desaparecida. Del lado oriental de esta sala tampoco queda nada sobre la rasante del primitivo pavimento, sólo ha llegado hasta nosotros la cimentación. También aquí se producía un retalle entre ésta y el arranque de los muros de alrededor de $15 \mathrm{~cm}$, aunque en dos de los lados existe otro segundo retalle de similares dimensiones, probablemente dispuesto para regularizar la planta de la sala quizás no

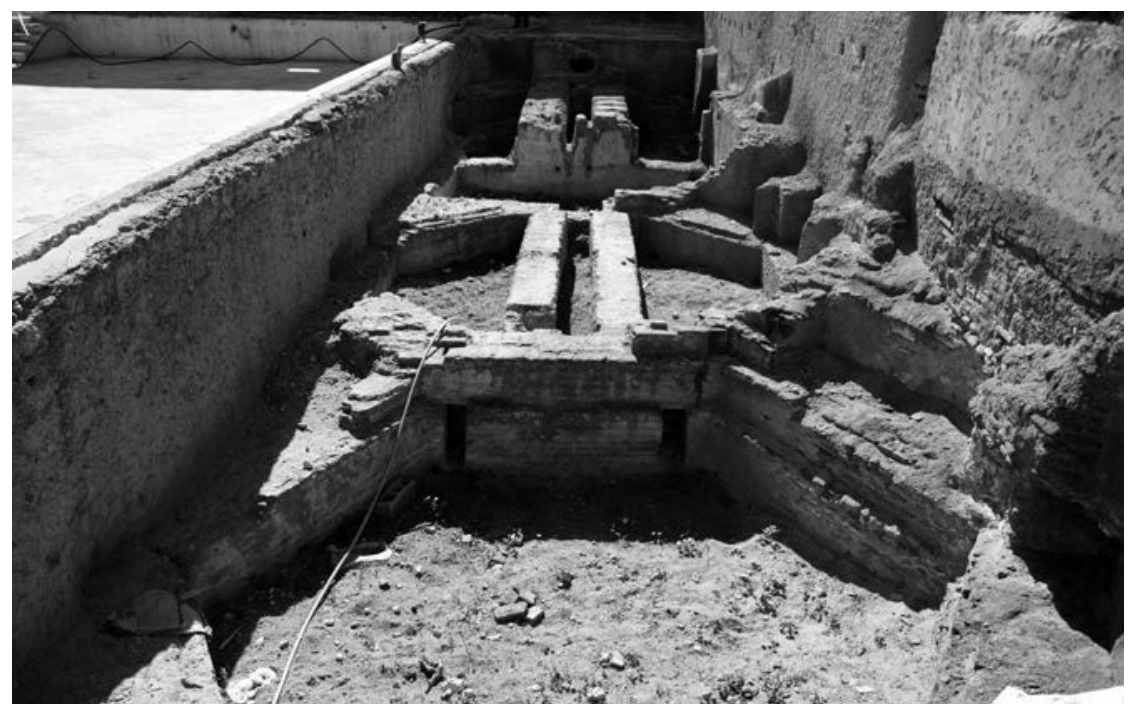

Figura 7. Vista de la sala caliente del baño (A. Almagro). 
bien replanteada en la cimentación. La excavación de esta sala también se bajó hasta una cota bastante por debajo del pavimento, pero en este caso con toda razón ya que sin duda alguna aquí sí existió un hipocausto o espacio bajo el pavimento que servía para su caldeamiento. Esto viene refrendado por la presencia dentro de la cimentación de dos huecos verticales a ambos lados de la puerta de acceso cuya salida superior tiene planta cuadrada de unos $0.18 \mathrm{~m}$ de lado y que tendrían continuidad en la parte alzada de los muros hasta alcanzar su coronamiento. En la zona inferior presentan unas aberturas verticales de unos $0.18 \mathrm{~m}$ de ancho por unos $0.50 \mathrm{~m}$ de altura que permitiría al humo acceder a los conductos verticales alojado dentro de los muros (Fig. 7).

En la zona opuesta a la entrada, la cimentación presenta un gran boquete de alrededor de $2 / 3$ de su longitud que puede haberse formado al desaparecer el arco por el que el hipocausto se comunicaba con el hogar donde se calentaba el agua. Como más allá de este punto la excavación no prosiguió, no es posible dar más precisiones sobre este extremo. Dada la situación actual del yacimiento, tampoco es posible precisar nada sobre el modo de cubrición del hipocausto ya que no se ha conservado ningún soporte ni es posible identificar ninguna huella de ellos en el suelo. Lo más probable es que hubiera una serie de pilarcillos de ladrillo en los que se sustentarían bovedillas, seguramente realizadas por aproximación de hiladas de ladrillo. En el perímetro, se aprovecharía el retalle de la cimentación para el apoyo de estas estructuras.

\section{Identificación e interpretación de estas estructuras}

La presencia, en la última sala descrita, de unos conductos de salida de humos y la más que segura existencia de un hipocausto nos llevan de inmediato a identificar estas estructuras como pertenecientes a un baño. Pero hay que decir de inmediato que la forma que presenta esta serie de habitaciones resulta sumamente anómala respecto de los baños que conocemos en el Magreb y en al-Andalus ${ }^{6}$. No obstante, la disposición de las tres habitaciones principales formando una suite que hay que recorrer desde la que puede suponerse como entrada hasta la más lejana sí encajaría con las estructuras características de un hammām (Fig. 8).

\footnotetext{
${ }^{6}$ Fournier, Les bains d'al-Andalus, pp.153-182.
} 


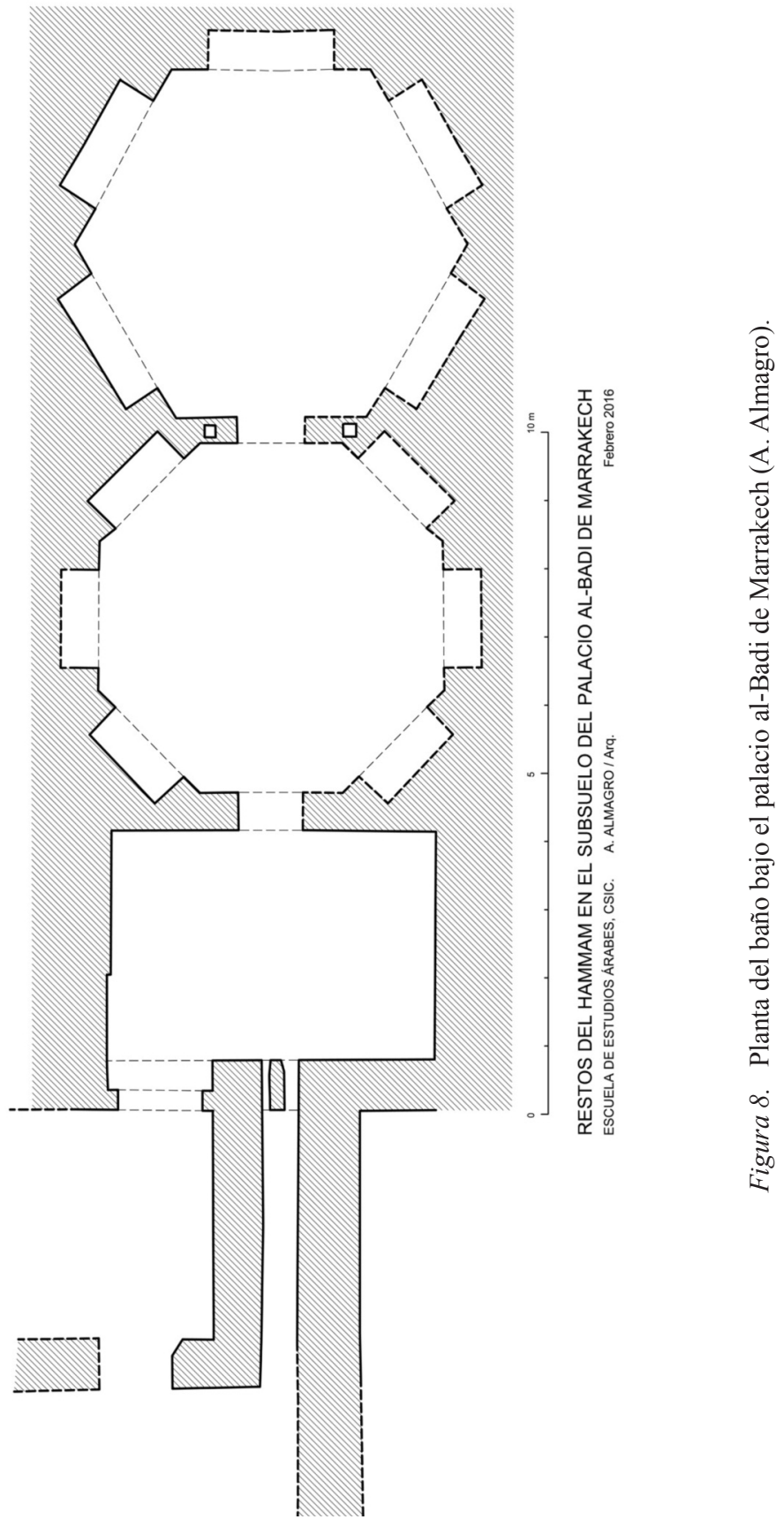


Según esto, la sala de planta hexagonal situada más al norte de las tres y dotada de hipocausto sería la sala caliente o bayt al-sajūn. Más al norte de ésta se situarían los espacios de servicio con el horno y la caldera que no han sido excavados. Siguiendo la pauta de otros baños, una pared de escaso espesor separaría la sala caliente de la caldera para que sirviera también de transmisor de calor. Por debajo del pavimento un arco, o más bien bóveda, pondría en comunicación el espacio del hipocausto con el hogar y serviría de tiro para éste de forma que, al producirse una corriente, el humo y el calor se extenderían por este espacio dispuesto bajo el pavimento de la sala. El humo se dirigiría hacia las dos chimeneas alojadas dentro del espesor del muro que separa esta sala de la inmediata. La existencia de chimeneas y de un espacio para el hipocausto en esta sala es sin duda el argumento principal para la identificación que proponemos, toda vez que no conocemos en el mundo islámico y menos en el norte de África, que se hayan utilizado este tipo de estructuras para caldear otro tipo de espacios.

La siguiente habitación, con planta octogonal, sería el bayt alwasțānī o sala templada. Ya hemos indicado que no es posible sostener la existencia de un hipocausto en esta sala, cosa que no resulta por otro lado anómalo, ya que en la mayoría de los baños andalusíes las salas templadas no tienen hipocausto o a lo sumo sólo pasa bajo ellas algún conducto de salida de humo. Tanto en esta sala como en la anterior, los nichos pudieron incluir bancos de fábrica en su zona baja para proporcionar asiento a los usuarios del baño.

La sala de planta rectangular sería la sala fría o bayt al-bārid. Ya indicamos que por la presencia de rozas abiertas en el muro meridional cabría suponer que en ese lugar hubo una pila que forzosamente sería de agua fría dada su lejanía del emplazamiento del hogar. Por esta sala se produciría la entrada al baño propiamente dicho o a sus salas húmedas y por tanto construidas con materiales más sólidos y seguramente cubiertas con bóvedas. La habitación inmediata, que sólo conocemos parcialmente, pudo haber sido la sala de reposo o dār al-mașlaḥ, o un simple espacio de paso desde aquella hasta la zona húmeda. Esto es difícil de ser precisado al no conocerse el entorno de estas habitaciones. Como por su emplazamiento y por sus características que luego analizaremos hemos de suponer que este hammām perteneció al palacio real o alguna de las residencias de la qaṣba, se antoja que el dār al-mașlaḥ tuvo que tener mayor tamaño y prestancia que la que insinúa esta ha- 
bitación, pues seguramente sería una sala con linterna, a juzgar por lo que conocemos de otros baños.

Todas estas salas debieron estar cubiertas con bóvedas que incluirían lucernas para su iluminación. La sala fría podemos pensar que tuvo una bóveda de cañón o quizás de espejo. Las otras dos debieron contar con bóvedas de tantos paños curvos como lados tenía la sala. Por lo que puede apreciarse parece que los muros fueron de ladrillo al menos en las dos salas calientes y hay que pensar que las bóvedas estarían construidas con el mismo material. Ya vimos que, en la sala fría, el muro meridional era de hormigón, al menos hasta la altura con que se ha conservado. Nada podemos decir ni de los pavimentos ni de los revestimientos internos ya que nada de esto se ha conservado. Tampoco tenemos información sobre los dispositivos hidráulicos pues por la poca altura que han conservado los muros (apenas $0.40 \mathrm{~m}$ en el lado occidental y sólo la cimentación en el oriental, no se pueden analizar posibles rozas o pasamuros. Tampoco podemos precisar si existió alguna pila de agua caliente en la sala más septentrional.

\section{Paralelos y cronología}

Ya hemos apuntado anteriormente que, en su morfología, los distintos ámbitos de este baño resultan bastante anómalos en el occidente musulmán. En al-Andalus, desde los primeros baños que conocemos de Madīnat al-Zahrā', las salas son generalmente rectangulares y alargadas, puestas en paralelo y cubiertas con bóvedas de cañón. Más adelante, la sala templada tiende a ampliar su tamaño pasando en ciertos casos a ser cuadrada e incluso a disponerse galerías perimetrales en varios de sus lados. Las salas frías o son en ocasiones inexistentes o son en general de igual o menor tamaño que las calientes, aunque siempre con planta rectangular ${ }^{7}$. Pero plantas hexagonales u octogonales como existen en este baño es algo inédito en el occidente islámico. Por lo que conocemos en el Magreb, las pautas son bastante similares ${ }^{8}$. Incluso en Argelia, donde la presencia otomana desde el segundo cuarto del siglo

${ }^{7}$ Almagro, "Dibujar la arquitectura de al-Andalus", fig. 8; Fournier, Les bains d'alAndalus, figs. 31-42.

${ }^{8}$ Terrasse, "Trois bains mérinides du Maroc"; de Miranda, L'hammam nell'Islam occidentale fra l'VIII e il XIV secolo. 
XVI tuvo indudables efectos en la disposición de los baños, no encontramos salas con esta disposición. Así, los baños de época otomana se caracterizan por reducir el tamaño de la sala templada y disponer las salas calientes con planta cuadrada ${ }^{9}$. Esto nos lleva forzosamente a buscar posibles paralelos en otras áreas del mundo islámico.

Los baños omeyas orientales tienen en su mayoría las salas húmedas con planta cuadrada, generalmente cubiertas con bóvedas de arista las templadas y con cúpulas las calientes. Sólo en Jirbat al-Mafyar la sala caliente tiene planta circular o más bien octogonal con ocho alveolos semicirculares. ${ }^{10}$

En períodos posteriores se produce una cierta mayor complejidad en las formas y disposición de los espacios. En época silŷūqí las salas calientes empiezan a tener formas cruciformes ${ }^{11}$ que serán adoptadas por los otomanos. También desde época ayyūbí existen salas octogonales ${ }^{12}$. Con estos, y especialmente con la efusión constructiva que acompaña a su gran expansión territorial y su conversión en una gran potencia, se consolida un modelo que presenta ciertas diferencias respecto al hammām de periodos anteriores. Se puede decir que el baño se simplifica reduciéndose a dos grandes espacios, el vestuario y sala de reposo y la sala caliente, con una habitación intermedia de menores dimensiones que facilita la acomodación térmica y desde la que se accede habitualmente a las letrinas. La sala de reposo y vestuario es siempre cuadrada cubierta con cúpula, mientras la sala caliente adopta formas diversas, aunque también con cubierta cupuliforme.

Entre las variadas formas que se adoptan para las salas calientes encontramos con frecuencia las cruciformes y las octogonales, pero también hay presencia de plantas hexagonales. La forma hexagonal está presente con cierta asiduidad en el período clásico de la arquitectura otomana ${ }^{13}$, representada principalmente por la figura de Sinán,

${ }^{9}$ Cherif-Seffadj, "The Medieval and Ottoman Hammams of Algeria”, p. 165; "Les bains algériens", figs. 19-23.

${ }^{10}$ Almagro, Qusayr 'Amra. Residencia y baños omeyas en el desierto de Jordania, pp.115-118.

${ }^{11}$ Kuran, Sinan, el maestro de la arquitectura otomana, p. 123.

${ }^{12}$ Sauvaget, "Un bain damasquin du XIII" siècle".

${ }^{13}$ En la obra de Sinán son frecuentes las mezquitas cuya cúpula central se apoya sobre una estructura de planta hexagonal: mezquita de Sinan Paşa, Beşiktaş; mezquita-madraza de Sokullu Mehmed, Kadirga; mezquita-madraza de Kara Ahmed Paşa, Topcapi; mezquita de Molla Çelebi, Findikli; mezquita de Kazasker Ivaz Efendi, Eğrikapt; mezquita de Valide Atik, Toptaşi (Kuran, Sinan, el maestro de la arquitectura otomana, pp. 126, 132, 136, 143, 224). 


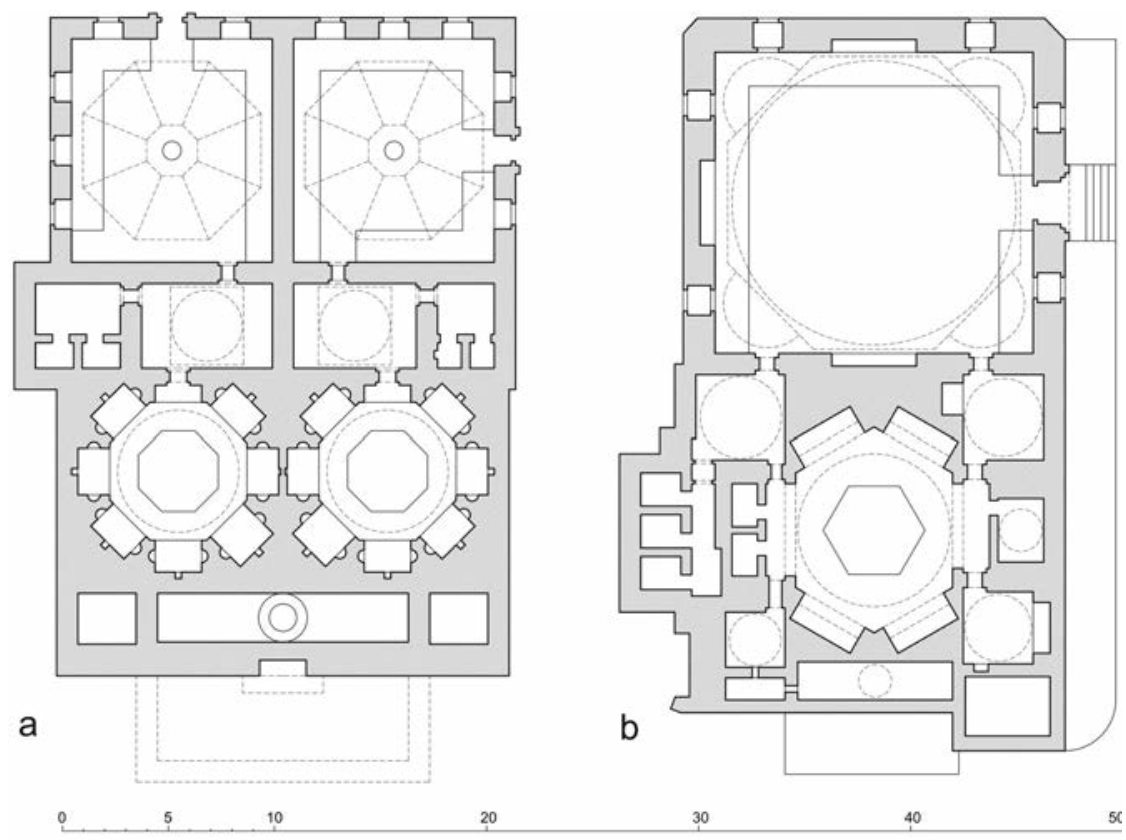

Figura 9. Planta de baños otomanos: a. complejo de Pertev Mehmet Paşa, en Estambul; b. complejo de Kiliç Ali, en Tophane (reelaboración a partir de datos tomados de https://archnet.org/sites/2793, https://archnet.org/sites/1999).

quien en su prolífica obra cuenta también con la construcción de varios baños.

La planta octogonal es seguramente la más utilizada, sobre todo con grandes nichos en cuatro lados que acaban confiriendo un aspecto cruciforme al espacio, y con puertas en los otros cuatro lados por las que se accede a pequeñas habitaciones auxiliares usadas para masajes y otros tratamientos que ocupan los espacios que quedan entre los brazos de la cruz ${ }^{14}$. Pero también encontramos salas de planta octogonal con nichos en todos sus lados y, por tanto, sin llegar a aparentar forma de cruz, como en el baño del complejo de Pertev Mehmet Paşa construido entre 1572 y 1580 en Estambul (Fig. 9a). La forma hexagonal es más

${ }^{14}$ Un ejemplo característico es el del baño de Haseki Sultán, cercano a Santa Sofía en Estambul (Kuran, Sinan, el maestro de la arquitectura otomana, p. 118). 
rara en los baños pero tenemos un caso muy interesante en el hammām perteneciente al complejo de Kiliç Ali, en Tophane ${ }^{15}$ (Fig. 9b), concluido en 1583, y que presenta nichos rectangulares de poca profundidad en cinco de sus lados, mientras que en el sexto se abre un espacio más amplio cubierto con cúpula.

Todos estos paralelos nos conducen indefectiblemente a considerar que este baño se hizo teniendo como referentes los que en la segunda mitad del siglo XVI se construyeron en el imperio otomano, y aunque el esquema general del baño, con las salas templada y caliente del mismo tamaño, se puede decir que sigue siendo el tradicional en el occidente islámico, la introducción de salas de planta central tanto octogonal como hexagonal fue sin duda una innovación tomada de los modelos otomanos clásicos.

La cuestión inmediata que se plantea es quién y cuándo ha podido realizar esta obra dentro de la qașba de Marrakech. En principio tendríamos una clara fecha ante quem que es la del inicio de la construcción del palacio al-Badī‘ en 1578. Como indicamos al comienzo, estas estructuras estaban ya derruidas o lo fueron a causa de la construcción del nuevo palacio. El muro de cierre del patio se apoya claramente en algunos de los muros de este baño ya arruinados (Figs. 5 y 6 ) a la vez que maciza parte de los nichos de las salas templada y caliente (Fig. 3). Por su parte, la construcción de la alberca del ángulo noroeste del patio del nuevo palacio cercenó igualmente parte de las cimentaciones del lado oriental y es evidente que en ese momento los muros superiores ya se habían demolido. Por tanto, lo que cabe asumir es que el baño fue demolido para hacer posible la construcción del palacio. Teniendo en cuenta que el palacio se empezó a edificar el mismo año del acceso al trono de Aḥmad al-Manșūr, no cabe atribuirle a él su construcción y hemos de pensar en otro de los sultanes que le precedieron en la segunda mitad del siglo XVI.

La influencia otomana en el Mediterráneo occidental empieza a aparecer a raíz del reconocimiento por parte de los corsarios argelinos de la autoridad de la Sublime Puerta y de la ocupación de Argel y de Túnez por los Barbarroja en la tercera década del siglo XVI. No cabe pensar que la influencia de la arquitectura otomana haya podido alcanzar Marruecos antes del advenimiento de la dinastía sa'adí, e incluso con ella hay que tener muchas reservas al respecto.

${ }^{15}$ Kuran, Sinan, el maestro de la arquitectura otomana, pp. 252, 261. 
El primer sultán sa‘adí, Muhammad al-Šayj (1544-1557) hubo de hacer frente a la alianza de los watțāsíes con los otomanos cuya política expansiva pretendía llevar su imperio hasta el Atlántico. Finalmente fue asesinado en 1557 por agentes otomanos infiltrados en su propia guardia personal. La presencia otomana en la vecina Argelia fue causa de problemas también en el reinado de su hijo y sucesor 'Abd Allāh al-Gālib (1557-74). Durante su gobierno, sus hermanos 'Abd al-Malik y Ahmad, potenciales herederos del trono según la costumbre, se vieron forzados a exiliarse en el imperio turco para evitar ser asesinados y que de este modo la sucesión pasara directamente al hijo de 'Abd Allāh. En los 17 años de exilio del heredero legítimo, 'Abd al-Malik, éste se asentó en Argel aunque realizó numerosos viajes por el imperio y estuvo en diversas ocasiones en Estambul ${ }^{16}$. Sus actividades al servicio de los otomanos son bien conocidas, como la participación en la batalla de Lepanto y en la toma de La Goleta por los turcos, ocurrida en el mismo año de la muerte de su hermano mayor 'Abd Allāh. Con la ayuda militar conseguida mediante un pacto con Murād III ${ }^{17} \mathrm{y}$ las hábiles gestiones de su hermano Aḥmad actuando de incógnito como agente en el país, consiguió hacerse con el trono, obligando a exiliarse a su sobrino Muhammad al-Mutawakkil (1574-1576), hijo y sucesor de 'Abd Allāh. El recurso de éste a una alianza con Portugal llevó a la intervención de Sebastián I en una campaña que acabó en la desastrosa derrota de Alcazarquibir (1578), también conocida como la Batalla de los Tres Reyes, pues en ella perecieron D. Sebastián de Portugal, Muhammad y 'Abd al-Malik. Las consecuencias de esta batalla fueron de enorme trascendencia, no solo en el orden interno, sino a nivel internacional. Con la muerte de Sebastián y al carecer de sucesión, Portugal quedó unida a España y en Marruecos ascendió al trono el hijo menor de Muḥammad al-Šayj, Aḥmad al-Manșūr, sin duda el sultán sa'adí que alcanzó mayor renombre.

Esta breve reseña histórica pone de manifiesto que el único momento en que existieron condiciones para una posible penetración de la influencia otomana en gustos y costumbres en el Marruecos sa'adí

\footnotetext{
${ }^{16}$ García-Arenal, Ahmad al-Mansur: The Beginnings of Modern Morocco, p. 23.

${ }^{17}$ al-Ifrani, Nozhet-Elhâdi, histoire de la dynastie saadienne au Maroc, pp. 59 y 62 (105 y 109 de la traducción).
} 
antes de Ahmad al-Manșūr ${ }^{18}$ fue durante el breve gobierno de 'Abd alMalik (1576-1578). Como ya hemos indicado, este sultán pasó una parte importante de su vida al servicio de los otomanos de quienes asimiló sus tácticas militares y de organización y adiestramiento del ejército, entre otras cosas. Además, su madre también se exilió en Estambul colaborando con su hijo en las negociaciones que propiciaron la ayuda turca para recuperar el trono. La constante pugna mantenida con los otomanos durante los gobiernos de Muhammad al-Šayj y 'Abd Allāh al-Gālib hacen de todo punto impensable que hubiera una influencia turca en la arquitectura marroquí durante su reinado. De hecho, las obras conservadas de 'Abd Allāh, la mezquita al-Muwāssīn y la madraza Ben Yūsuf, muestran únicamente una clara continuidad con las formas y modelos tradicionales, especialmente de la arquitectura meriní. ${ }^{19}$

No conocemos ninguna construcción que pueda atribuirse al reinado de 'Abd al-Malik que, por otro lado, dada su brevedad, difícilmente pudo dar lugar a grandes obras. Pero su larga estancia entre los ámbitos de poder del imperio turco pudo muy bien haber influido en una iniciativa de este tipo ${ }^{20}$. Este baño, dista mucho, por su tamaño, de poderse comparar con las grandes construcciones termales del momento de mayor esplendor de la arquitectura otomana, además de que muestra una clara continuidad con el esquema tradicional de los baños del occidente musulmán. Pero el recurso a formas y modelos espaciales tomados de los hammāms que se estaban construyendo en Estambul en esa época puede estar mostrando tanto deseos de innovación como de una cierta vinculación con la gran potencia política y militar del Mediterráneo, con cuya ayuda se había hecho con el poder. Por todo ello creo que resulta bastante verosímil atribuir esta construcción al sultán sa'adí 'Abd al-Malik y fecharla entre los años 1576 y 1578. Es cierto que los edificios que mencionamos como posibles inspiradores serían prácticamente contemporáneos del que nos ocupa, pero bien pudieron

${ }^{18}$ De la influencia de la arquitectura otomana en el palacio al-Badī‘ me he ocupado en un trabajo reciente (Almagro, "El palacio sa'adí al-Badi' (Marrakech). Entre al-Andalus y el Egipto mameluco").

${ }^{19}$ Marçais, L'architecture musulmane d'Occident, p. 385.

${ }^{20} \mathrm{Su}$ cosmopolitismo y su admiración por los usos y costumbres otomanos han sido resaltados por García-Arenal, (Ahmad al-Mansur: The Beginnings of Modern Morocco, p. 31).

Al-Qanțara XXXVIII 2, 2017, pp. 263-285 ISSN 0211-3589 doi: 10.3989/alqantara.2017.009 
ser conocidos sus proyectos o visitadas sus obras por el futuro sultán sa'adí o por allegados a él en el transcurso de sus estancias en Estambul, aparte de que las formas octogonales y hexagonales están presentes en obras otomanas anteriores.

Aunque dos años pueda parecer un tiempo demasiado breve para la realización de una obra arquitectónica, no lo es para una de carácter menor como la que nos ocupa. Hemos de tener en cuenta que por su ubicación este baño debía estar inmediato a la zona de la qaṣba en que se hallaba la residencia del sultán ${ }^{21} \mathrm{y}$, por tanto, cabe imaginar que se trataba de un baño a él destinado. La decisión de su hermano y sucesor de construir el gran palacio al-Badī', motivada en gran medida por razones de conveniencia política, convertiría en efímero este edificio termal que quizás aún pudo mantenerse en uso durante algún tiempo mientras duraba la construcción del nuevo palacio que se desarrolló durante un lapso de tiempo relativamente largo, de casi dieciséis años. Lo que resulta indudable es que estas estancias, destinadas como suponemos a baño, interferían en el proyecto del nuevo palacio por lo que su destrucción resultó inevitable, produciéndose con ello la reubicación del hammām palatino en la zona más al sur según se deduce de la descripción de al-Fištālī. ${ }^{22}$

\section{Agradecimientos}

Este trabajo se ha desarrollado en el marco del proyecto de investigación HAR2014-53006-P, "Arquitectura Sa'adí. La pervivencia de al-Andalus en el Magreb (ARSA)", financiado por el Ministerio de Economía y Competitividad, Programa Estatal de Fomento de la Investigación Científica y Técnica de Excelencia, cofinanciado por los Fondos FEDER de la Unión Europea.

${ }^{21}$ Koehler, "La Kasba saadíenne de Marrakech", pp. 8-10.

22 al-Fištâlī, Manāhil al-Ṣafă', p. 180. 


\section{Bibliografía}

Almagro, Martín, Caballero, Luis, Zozaya, Juan y Almagro, Antonio, Qusayr 'Amra. Residencia y baños omeyas en el desierto de Jordania, Granada, Fundación El Legado Andalusí, 2002 (reedición).

Almagro, Antonio, “Análisis arqueológico del pabellón occidental del palacio AlBadi' de Marrakech", Arqueología de la Arquitectura, 10, (2013) enero-diciembre 2013, e008, http://dx.doi.org/10.3989/arq.arqt.2013.002.

Almagro, Antonio, "Dibujar la arquitectura de al-Andalus: la base de un método de Investigación", en Pilar Chías Navarro y Vito Cardone (dir.), Dibujo y arquitectura. 1986-2016, treinta años de investigación, Alcalá de Henares, Universidad de Alcalá, 2016, pp. 2-15.

Almagro, Antonio, "El palacio sa'adí al-Badi“ (Marrakech). Entre al-Andalus y el Egipto mameluco", Las artes en Al-Andalus y Egipto. Contextos e intercambio, Madrid, La Ergástula, 2017, pp. 27-49.

Cherif-Seffadj, Nabila, "The Medieval and Ottoman Hammams of Algeria; Elements for a Historical Study of Baths Architecture in North Africa", ArchnetIJAR, Volume 3 - Issue 1 -March 2009, pp. 157-170.

Chérif-Seffadj, Nabila, "Les bains algériens, architecture, fonctionnement et gestion. Entre apports andalous et modèles ottomans", en M.-Fr. Boussac, S. Denoix, Th. Fournet y B. Redon (dir.), 25 siècles de bains collectifs en Orient, El Cairo, Institut français d'archéologie orientale, 2014-15, vol. I, pp. 233-263.

Deverdun, Gaston, Marrakech, des origines à 1912, Casablanca, Éditions Frontispice, 2004.

al-Fištālī, 'Abd al-'Aziz, Manāhil al-Ṣafā fì ma'ātir mawālī-nā al-šurafā', ed. 'Abdallah Guennun, Rabat - Tetuán, Faculté des Lettres - Institut Moulay El-Hassan, 1964.

Fournier, Caroline, Les bains d'al-Andalus VIIIe-XVe siècle, Rennes, Presses Universitaires de Rennes, 2016.

García-Arenal, Mercedes, Aḥmad al-Manșūr: The Beginnings of Modern Morocco, Oxford, Oneworld, 2009.

al-Ifrani, Muḥammad Sagir, Nozhet-Elhâdi, histoire de la dynastie saadienne au Maroc (1511-1670), trad. al francés por O. Houdas, París, Ernest Leroux, 1888-1889.

Koehler, Henry, "La Kasba saadienne de Marrakech, d'après un plan manuscrit de 1585", Hesperis, 27 (1940), pp. 1-20.

Kuran, Aptullah, Sinan, el maestro de la arquitectura otomana, Granada, Universidad de Granada, 1997.

Marçais, Georges, L'architecture musulmane d'Occident. Tunisie, Algérie, Maroc, Espagne, Sicile, París, Arts et métiers graphiques 1954.

Mármol Carvajal, Luis del, Descripción general de África, Tomo I, Granada 1573, (Reedición: Madrid, Instituto de Estudios Africanos, 1953). 
de Miranda, Adriana, L'hammam nell'Islam occidentale fra l'VIII e il XIV secolo, Roma, L'Erma di Bretschneider, 2010.

Sauvaget, Jean, "Un bain damasquin du XIII' siècle”, Syria, 11 (1930), pp. 370380.

Terrasse, Henri, "Trois bains mérinides du Maroc", Melanges offerts à William Marçais par l'Institut d'Études Islamiques de Paris, Paris, Maisonneuve, 1950, pp. 311-320.

Recibido: $11 / 07 / 2016$

Aceptado: 12/08/2017 